\title{
Desain Intruder Detector System di Laboratorium Komputer SMKN 1 Tondano dengan Arsitektur CCTV
}

\author{
John Reimon Batmetan, Mercylia Moningkey, Darma Poluan, Armando Sumera \\ Jurusan Pendidikan Teknologi Informasi dan Komunikasi, Universitas Negeri Manado \\ Kampus UNIMA-Tondano, Minahasa 95618 Indonesia \\ john.reimon@gmail.com, mercylia.jillsy@gmail.com,dharmafijay003@gmail.com, armandosumera@gmail.com
}

\begin{abstract}
ABSTRAK
Kebutuhan manusia akan sistem pemantauan terhadap tempat-tempat tertentu semakin meningkat. Sehubungan dengan hal tersebut Laboratorium Komputer milik sekolahpun tidak luput dari para pengganggu keamanan. Pengganggu keamanan atau dalam bahasa inggris biasa disebut dengan "intruder". Intruder dapat berupa pencuri, perusak, maupun pengacau keamanan. Pada paper ini, kami akan meneliti desain dari arsitektur CCTV Laboratorium Komputer sekolah untuk meneliti tentang hasil implementasi Desain sistem pendeteksi intruder yang menggunakan arsitektr CCTV dengan SMK N 1 Tondano sebagai lokasinya dan melakukan observasi terhadap tempat-tempat serta area yang diperbolehkan. Hasil dari penelitian ini adalah rumusan tentang pengaruh terhadap kinerja dalam mendeteksi intruder di SMK N 1 Tondano yang kami dapatkan melalui observasi dan wawancara secara langsung serta dengan dukungan teori buku-buku, jurnal, internet dan sumber lainnya.
\end{abstract}

Kata Kunci : Desain, Intruder, Laboratorium Komputer Sekolah, CCTV

\section{PENDAHULUAN}

Perancangan yang tepat akan menghasilkan hasil yang sesuai dengan keinginan kita. Sehubungan dengan hal tersebut, tentunya kita dapat menemukan makna bahwa suatu perancangan atau desain yang dibuat secara matang akan meminimalisir segala hal yang tidak diinginkan pada saat melakukan uji coba atau implementasi.

Kebanyakan orang tidak serius ketika berada pada tahap perancangan. Ada beberapa yang melewatkan beberapa aspek dan poin-poin penting ketika mereka mulai mendesain sehingga hasil yang didapatkan tidak sesuai dengan ekspetasi.

Sehubungan dengan hal diatas, SMK Negeri 1 Tondano belum lama ini melakukan pemasangan CCTV dalam rangka meningkatkan keamanan sekolah. Pemasangan dilakukan untuk meminimalisir terjadinya tindak kejahatan diarea sekolah SMK N 1 Tondano terutama pada tempattempat tertentu seperti Laboratorium Komputer.

Disini kami akan mengevaluasi Desain sistem yang digunakan untuk mengetahui pengaruh terhadap kinerja dalam mendeteksi intruder diSekolah SMK N 1 Tondano yang dihasilkan lewat wawancara serta observasi langsung ditempat pengamatan.

\section{KAJIAN TEORI}

Desain

Desain biasa diterjemahkan sebagai seni terapan, arsitektur, dan berbagai pencapaian kreatif lainnya. Dalam sebuah kalimat, kata "desain" bisa digunakan, baik sebagai kata benda maupun kata kerja. Sebagai kata kerja, "desain" memiliki arti "proses untuk membuat dan menciptakan obyek baru". Sebagai kata benda, "desain" digunakan untuk menyebut hasil akhir dari sebuah proses kreatif, baik itu berwujud sebuah rencana, proposal, atau berbentuk obyek nyata. Pawalnya desain merupakan kata baru berupa kata serapan dari kata design (bahasa Inggris), istilah ini melengkapi kata "rancang/rancangan/merancang" yang dinilai kurang mengekspresikan keilmuan, keluasan dan kewibawaan profesi (Sachary, 2002).

\section{Intruder}

Intruder merupakan kata yang berasal dari bahasa inggris. Artinya dalam bahasa Indonesia adalah pengacau.Pengacau dalam Kamus Bahasa Indonesia diartikan sebagai orang yang membuat kacau atau pengganggu keamanan (Sugono, 2008).

\section{Laboratorium Komputer Sekolah}

Dalam buku Kamus Besar Bahasa Indonesia Laboratorium, komputer dan sekolah disajikan dalam bentuk terpisah. Laboratorium dituliskan sebagai ruangan yg dilengkapi dengan peralatan khusus untuk melakukan percobaan, penyelidikan dsb. Komputer sendiri didefinisikan sebagai alat elektronik otomais yang dapat menghitung atau mengolah data secara cermat. Sedangkan kata "Sekolah" didefinisikan sebagai bangunan atau lembaga untuk belajar dan mengajar serta tempat menerima dan 
memberi pelajaran (menurut tingkatannya, ada). Secara garis besar. Laboratorium Komputer Sekolah dapat didefinisikan sebagai tempat untuk melakukan eksperimen atau riset yang berhubungan atau berkaitan dengan ilmu komputer yang terletak dalam lingkungan sekolah.

\section{CCTV}

Siaran sistem CCTV yang pertama dipasang oleh Siemens AG pada Test Stand VII di PeenemUnde, Jerman pada tahun 1942, untuk mengamati peluncuran roket V-2. Pada dekade belakangan ini, penggunaan kamera pengintai CCTV di ruang publik dapat lebih memperkecil resiko terjadinya kejahatan. CCTV adalah singkatan dari Closed Circuit Television. CCTV adalah camera video digital yang digunakan untuk mengirim sinyal gambar dari suatu tempat (Adriansyah, 2014). Umumnya CCTV digunakan untuk mengawasi area publik. Pada awalnya gambar dari CCTV hanya dikirim melalui kabel ke sebuah ruang monitor tertentu dan dijaga atau diawasi oleh petugas keamanan yang ditugaskan. Namun seiring dengan berjalannya teknologi, pemantauan dengan kamera CCTV dapat dimonitor atau dikontrol di mana saja dan kapan saja dengan Personal Computer atau telepon genggam selama terhubung dengan Internet atau jaringan GPRS.

Pada penggunaan kamera CCTV terdapat 2 pilihan untuk penggunaan kamera, yaitu IP WebCam dan IP Camera. IP Camera atau Internet Protocol Camera merupakan teknologi terkini yang sering digunakan untuk melakukan pengawasan pada ruang-ruang tertentu. Tentu harga dari pemakaian IP Camera tidaklah murah tetapi dalam segi kemajuan teknologi, IP Camera bisa dinyatakan lebih maju daripada WebCamera.

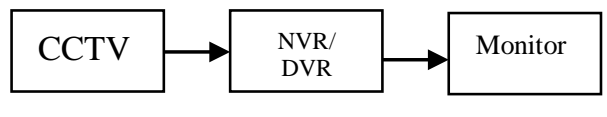

Gambar 1. Alur kerja CCTV

Komponen- Komponen untuk CCTV antara lain:

- Kamera : untuk kamera biasanya menggunakan jenis kamera Wide Angle supaya dapat menjangkau area lebih luas.

- Media Penghubung : Untuk penggunaan kabel, CCTV menggunakan kabel koaksial, sedangkan CCTV wireless kita menggunakan jaringan Internet dengan penghubung jembatan router atau Acces Point dengan menggunakan kabel $L A N$ untuk pemasangan dengan jenis CCTV IP Camera dengan konektor RJ45.

- Software : Ini merupakan aplikasi perangkat lunak yang dapat melakukan kontrol terhadap CCTV dari jarak tertentu.
- Penyimpanan : kita bisa menggunakan Harddisk untuk CCTV atau DVR (Digtal Video Recorder ) atau NVR ( Network Video Recorder) (Adriansyah, 2014)

\section{SMK Negeri 1 Tondano}

SMK Negeri 1 Tondano merupakan sekolah menegah kejuruan yang terletak di JIn. B.W Lapian Kelurahan Kembuan, Kecamatan Tondano Utara, Minahasa, Sulawesi Utara dengan kode Pos 95614. SMK Negeri 1 Tondano merupakan sekolah yang pada dasarnya berpusat pada sekolah pariwisata, tetapi ada juga beberapa program keahlian lainnya yang bersebrangan dengan jurusan pariwisata. Jurusan/Program Keahian yang terdapat disana antara lain : Tata Boga, Tata Busana, Akomodasi Perhotelan, Multimedia, Administrasi Perkantoran, dan Keperawatan.

SMK Negeri 1 Tondano memiliki visi dan misi sebagai berikut :

Visi : Terwujudnya Smk Negeri 1 Tondano Sekolah Yang Berkarakter Inovatif, Produktif, Dan Berdaya Saing.

Misi :

- Menumbuh kembangkan etos kerja yang handal bagi seluruh komponen yang ada disekolah.

- Menjadi peserta didik yang mampu berpikir rasional, santun, cakap, mampu bersaing, pantang menyerah dan menguasai IPTEK.

- Menyiapkan tamatan yang produktif sesuai bidang keahlian dan mampu beradaptasi dengan lingkungan kerja.

- Mengembangkan SDM yang mampu memanfaatkan kompetensi wisata daerah untuk meningkatkan taraf hidup masyarakat.

- Menjalin kerja sama untuk meningkatkan kualitas dan peran sekolah untuk masyarakat.

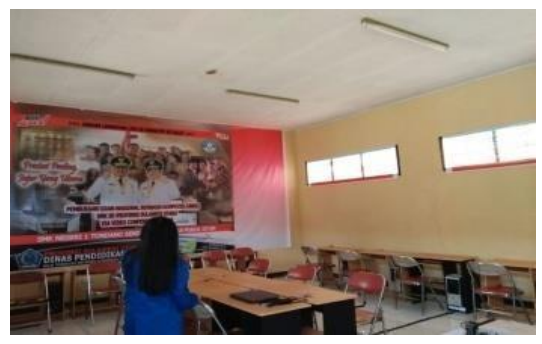

Gambar 2. Laboratorium Komputer SMKN 1 Tondano

SMK Negeri 1 Tondano memiliki 2 ruangan Laboratorium komputer yang terletak pada bagian tengah belakang Sekolah SMK N 1 Tondano. Setiap ruangan memiliki 1 CCTV yang diletakan diatas pintu masuk dan diawasi/dikontrol lewat ruang kontrol yang berada pada ruangan kepala sekolah dan dikontrol langsung oleh kepala SMK Negeri 1 Tondano yakni Bpk. Vecky Pangerapan M.Pd. Karena tata letak 
ruang Laboratorium Komputer SMK N 1 Tondano memiliki kesamaan maka peletakan CCTV pun diletakan pada tempat yang sama.

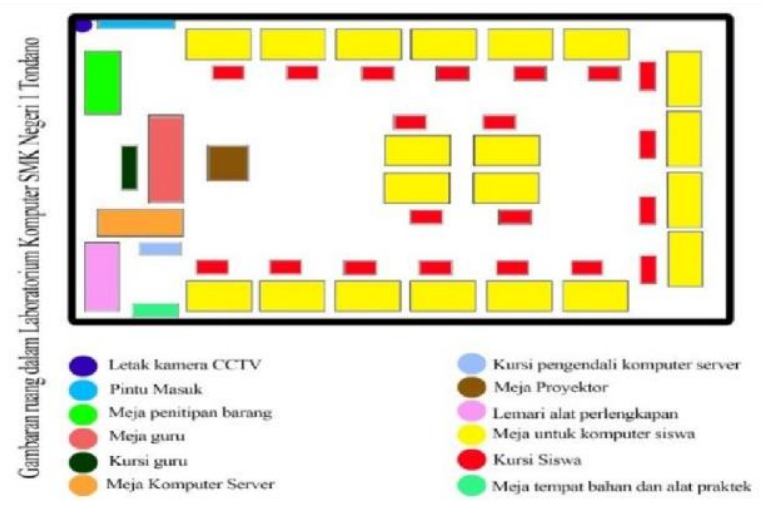

Gambar 3. Tata letak ruangan Laboratorium komputer SMK N 1 Tondano

\section{METODE PENELITIAN}

Metode yang kami gunakan adalah metode penelitian kualitatif. Pada pendekatan kualitatif, jenisjenis bidang pendekatan ialah etnografis, tugas lapangan, soft data, interaksionisme simbolik, naturalistik, deskriptif, pengamatan dengan keterlibatan peran, phenomenologik, data dokumenter, studi kasus, studi sejarah deskriptif, dan studi lingkungan kehidupan, observasi, review dokumen partisipan observer dan story (Musianto, 2002).

Pada penelitian ini, langkah-langkah yang kami lakukan adalah dengan mengidentifikasi masalah, studi awal terkait kajian teori, observasi lapangan serta wawancara inklusif dengan pihak-pihak terkait yang dapat memberikan informasi yang akurat serta dapat dipercaya.

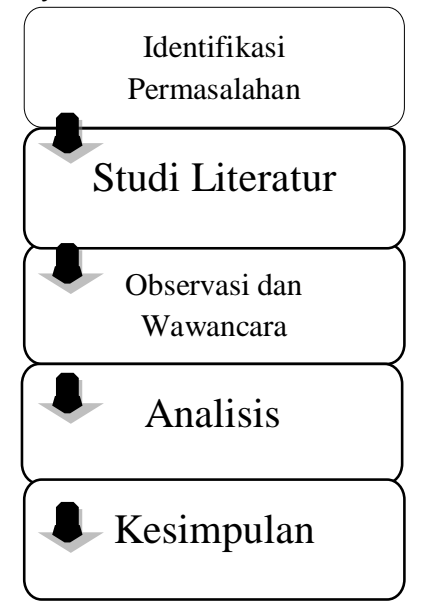

Gambar 4. Alur Metode Penelitian

\section{HASIL DAN PEMBAHASAN}

\section{Desain Dan cara kerja Sistem CCTV}

Untuk memudahkaan kami dalam mengklasifikasikan hasil analisa desain dan cara kerja sistem CCTV didalam laboratorium SMK N 1 Tondano kedalam bentuk $5 W+1 H$.

\section{What}

CCTV yang digunakan adalah CCTV dengan jenis IP Dome Camera. IP Dome camera adalah sebuah produk elektronik yang ditempatkan pada lokasi yang tidak dapat dipantau dan digunakan untuk merekam kejadian yang terjadi di suatu lokasi. IP Dome Camera terdiri dari bagian seperti kamera megapixel resolusi tinggi mulai dari 0,3 hingga 29 megapixel dan menggunakan lensa wide dengan jarak fokus mulai dari $3.6 \mathrm{~mm}$ hingga $12 \mathrm{~mm}$ tergantung luas lokasi yang dipantau (Setiawan, 2011). Berikut merupakan spesifikasi lengkap dari CCTV yang digunakan

\begin{tabular}{ll}
\hline Jenis & CCTV Dome IP Camera \\
\hline Merk & Panasonic \\
\hline Lensa & $2.88 \mathrm{~mm}$ Fixed Focuse \\
\hline Resolusi & $1.3 \mathrm{M}(1280 \times 960) / 720 \mathrm{p}(1280 \times 720) /$ \\
& D1 $(704 \times 480) /$ CIF $(352 \times 240)$ \\
\hline Frame & $1.3 \mathrm{M} / 720 \mathrm{p}(1$ - 30fps $)$ - D1/CIF $(1$ - \\
Rate & $30 f p s)$ \\
\hline Dimensi & $113 \times 28$ \\
\hline Berat & 200 including box \\
\hline Warna & Putih \\
\hline Sudut & 360 derajat \\
pantau & \\
\hline Pixel & $1280(H){ }^{*} 960(V)$ \\
\hline Power & $12 V$ DC \\
Supply & \\
\hline Record & Manual>Video Detect>Schedule \\
Priority & \\
\hline Storage & Network Storage \\
\hline Network & IPv4/6,HTTP,SSL,TCP/IP,UDP,UPnP,IC \\
Protocol & MP,FTP, SMTP,SNMP,DNS,dll \\
\hline Remote & Monitor, System SetUp, File Download, \\
Operation & log information, dll. \\
\hline
\end{tabular}

Where

Gambar 5. Tabel Spesifikasi CCTV

Kedua CCTV dilaboratorium SMK N 1 Tondano diletakkan tepat berada diatas pintu masuk laboratorium SMK N 1 Tondano, pada sudut 90 derajat. 


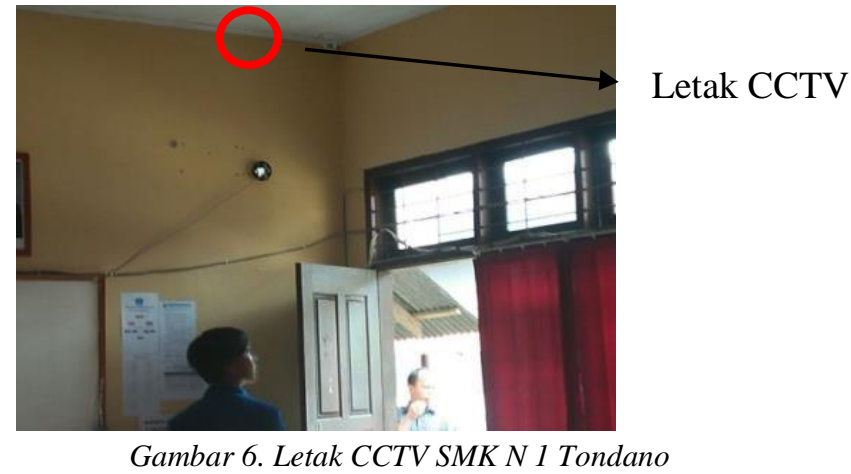

\section{When}

CCTV laboratorium SMK N 1 Tondano bekerja 1x24 jam. Room Control sendiri terletak pada Ruangan kepala SMK N 1 Tondano dengan kepala sekolah sebagai pengawas dan pengontrol langsung dari CCTV.

\section{Who}

CCTV dipasang untuk menghindari dan meminimalisir terjadinya tindak kejahatan ataupun kekacauan yang terjadi sewaktu jam belajar mengajar maupun sesudah jam sekolah. Yang diawasi tentunya seluruh masyarakat pengguna laboratorium serta siapa saja yang masuk kedalam laboratorium komputer SMK N 1 Tondano.

\section{How}

Perancangan sistem melibatkan teknisi dari luar sekolah dan dari dalam sekolah sehingga perancangan dapat disesuaikan dengan keadaan sekolah baik dalam segi ekonomi, sosial maupun lingkungan.

CCTV dikedua laboratorium SMK N 1 Tondano dihubungkan dengan cara mengambil alamat IP (Internet Protocol ) yang disambung melalui kabel RJ 45 ke Router yang terdapat di ruangan Laboratorium komputer untuk mendapatkan jaringan internet supaya dapat terhubung langsung ke NVR ( Network Video Recorder ) dimana ditempatkan pada ruangan Kepala SMK N 1 Tondano. Kemudian dari NVR disambungkan lagi melalui jaringan Internet/Wireless yakni menggunakan Access Point yang ada pada ruangan kepala SMK N 1 Tondano supaya dapat dihubungkan ke perangkat untuk monitoring rekaman langsung maupun tidak langsung dari ruangan yang terdapat CCTV dengan menggunakan software yang didownload dari perangkat sebagai jendela untuk monitoring.

CCTV dilengkapi cahaya night vision atau CCTV yang dapat melihat didalam gelap sehingga memudahkan pengontrol atau pemantau CCTV untuk mengenali siapa saja yang masuk kedalam ruangan laboratorium komputer sekolah pada saat malam hari dan apa yang dilakukan didalamnya. CCTV ini dilengkapi dengan fitur yang tidak memperkenankan orang yang melihat kearah CCTV dapat mendeteksi kemana arah pergerakan CCTV tersebut.

\section{Pengaruh terhadap kinerja dalam mendeteksi intruder di SMK N 1 Tondano}

Secara Teori, Desain Sistem yang digunakan pada laboratorium SMK N 1 Tondano termasuk pada desain sistem yang modern dan terintegrasi. Tentunya hal ini sangat membantu Pihak sekolah dalam mendeteksi adanya kegiatan tidak diinginkan dalam lingkungan sekolah.

Ada bermacam-macam efek yang dihasilkan dalam penggunaan CCTV pada kedua ruangan laboratorium SMK N 1 Tondano. Ini kami dapatkan melalui hasil observasi, wawancara langsung serta dukungan teori berupa jurnal dan buku-buku yang mendukung kami dalam proses penelitian. Efek yang dihasilkan antara lain :

Sebelum menggunakan CCTV :

- Adanya kerusakan elemen-elemen laboratorium oleh pihak-pihak tidak bertanggung jawab.

- $\quad$ Sering terjadi kehilangan barang pribadi maupun milik sekolah.

- Saat belajar sering terdengar keributan pada saat belajar mengajar.

Setelah menggunakan CCTV :

- Laboratorium Komputer SMK N 1 Tondano sudah lebih aman dan bebas tindak kejahatan.Karena menurut hasil wawancara dengan penanggung jawab Laboratorium Komputer, sebelum ada pemasangan CCTV Laboratorium komputer SMK N 1 Tondano sering kehilangan barang berharga serta adanya kerusakan-kerusakan yang dilakukan oleh tangan-tangan tidak bertanggung jawab.

- Siswa menjadi lebih tenang dalam melakukan aktivitas belajar mengajar diruangan laboratorium komputer karena adanya pengawasan CCTV yang langsung dimonitori oleh kepala SMK N 1 Tondano, walaupun ada sedikit rasa tegang karena merasa terus diawasi

- Masyarakat pengguna laboratorium komputer sekolah menjadi lebih berhati-hati ketika menggunakan barang-barang SMK N 1 Tondano.

\section{Kelebihan dan Kelemahan dari desain Sistem yang digunakan}

Setiap sistem yang digunakan tentunya memiliki kelebihan dan kelemahan. Kelebihan dan kelemahan ini kami dapatkan melalui survei, observasi dan wawancara, yang antara lain : 
Kelebihan

- Sistem yang digunakan sangat terencana dan sesuai dengan keadaan dari segi ekonomi, sosial dan lingkungan sekitar.

- Tidak sembarang orang dapat mengakses CCTV karena dilengkapi dengan login

Password untuk melihat jendela monitor CCTV.

- Penggunaan CCTV IP Dome Camera menghemat biaya dalam segi penggunaan kabel.

- Membantu pekerjaan dari satpam sekolah dan penjaga sekolah.

Kelemahan

- Karena menggunakan CCTV berbasis IP, IP Address dari kamera tersebut bisa diretas oleh pihak-pihak tidak bertanggung jawab dan dapat disalahgunakan untuk kepentingankepentingan lain.

- Sistem Monitoring satu orang tidak efektif dalam melakukan pengawasan.

- CCTV yang dipasang hanyalah CCTV pengawasan dimana pendeteksian penyusup tidak berjalan sewaktu CCTV aktif, tetapi dilakukan ketika tindak kejahatan sudah terjadi. Meskipun Lokasi dari labratorium komputer sekolah dekat dengan tempat tinggal penjaga sekolah serta adanya Satpam yang bekerja selama 1x24 jam, hal tersebut belum efektif dalam penjagaan.

\section{KESIMPULAN}

Berdasarkan pelaksanaan kegiatan penelitian dengan judul desain intruder detector system dilaboratorium komputer di smk $\mathrm{n} 1$ tondano dengan arsitektur CCTV dengan mendaatkan hasil lewat wawancara langsung serta observasi maka dapat disimpulkan bahwa :

1. Sampai saat ini penggunaan CCTV sangat membantu dalam menjaga fasilitas keamanan laboratorium komputer SMK N 1 Tondano.

2. Desain yang digunakan merupakan desain yang mengikuti kemajuan teknologi saat ini karena menggunakan Desain Sistem IP Camera.

Kami juga membuat masukan bagi pihak sekolah yakni dengan saran-saran antara lain : Untuk monitoring diharapkan bukan hanya diatur oleh satu orang tetapi harus ada lebih dari satu orang untuk menghindari terjadinya kekeliruan atau penyalahgunaan monitoring.

\section{DAFTAR PUSTAKA}

[1] Adriansyah, A. (2014). Rancangbangun dan analisa CCTV Online Berbasis Raspberry PI.

[2] RancangBangun CCTV , ISSN: 1410-233.

[3] Azanuddin. (2017). Aplikasi View Remote Camera CCTV Dengan Android Untuk Monitoring Kegiatan Mahasiswa Dilaboratorium Komputer Pada STMIK Budidarma Medan , 1-5.

[4] K. N. (2010). World Heritage City Surveillance System by a Smart CCTV System , 321-327.

[5] Hadiwijaya, B. (2014). Perancangan Aplikasi CCTV Sebagai Pemantau Ruangan, Transient, VOL.3, NO.2, JUNI 2014, ISSN: 2302-9927, 236.

[6] Haq, M. (2016). Rancang Bangun Cctv Dengan Sistem Camera Trap Menggunakan Sensor Pir Dan Kamera Ir Berbasis Raspberry PI , ISSN: 2302-9927, 126.

[7] Musianto, L. S. (2002). Aspek Pendekatan Metodologis. Perbedaan Pendekatan Kuantitatif dengan Pendekatan Kualitatif , $123-136$.

[8] Sachary, A. (2002). Sejarah dan perkembangan desain \& dunia kesenirupaan di Indonesia , 223-224.

[9] Setiawan, A. S. (2011). Pendahuluan. DESAIN CCTV IP CAMERA UNTUK ANGKUTAN UMUM KWK B14

[10] Sugono, D. (2008). Kamus Bahasa Indonesia. Jakarta: Kepala Pusat Bahasa.

[11] Suyatno. (2012). Pembangunan Local Area Network Laboratorium Akuntansi , ISSN: 2302-5700.

[12] J. R. Batmetan Suyoto, J. D. C. L. Suares, "An Empirical Investigation on Customer Behavior to Adopt Mobile Commerce among the $Y$ Generation in Indonesia", Sriwijaya International Conference On Engineering, Science \& Technology [SICEST 2016], 2016

[13] J.R. Batmetan, "Algoritma Ant Colony Optimization (ACO) untuk Pemilihan Jalur Tercepat Evakuasi Bencana Gunung Lokon Sulawesi Utara", Jurnal Teknologi InformasiAITI, 2016, vol.13, no.2, pp 31-48

[14] L. Madeso, D. R. Kabo, J. R. Batmetan, " Rancang Bangun Sistem Pakar Penentuan Status Gizi Pada Balita Menggunakan Metode Forward Chainning", E-Jurnal UNSRIT, vol.2

[15] J. R. Batmetan, V. R. Palilingan, " Higher Education Students' Behaviour to Adopt 
Mobile Learning", IOP Conference Series: Materials Science and Engineering, 2018, vol. 306, Issue 1, pp. 012110 (2018)

[16] V. R. Palilingan, J. R. Batmetan, " Incident Management in Academic Information System using ITIL Framework", IOP Conference Series: Materials Science and Engineering, 2018, vol. 306, Issue 1, pp. 012110 (2018)

[17] J. R. Batmetan, A. J. Santoso, Pranowo, " A Multiple-Objective Ant Colony Algorithm for Optimizing Disaster Relief Logistics", Advanced Science Letters, 2017, vol.23, no.3, pp. 2344-2347

[18] M. L. Tompodung, F. Supit, J. R. Batmetan, " Rancang Bangun Aplikasi Sensus Penduduk Berbasis Android", Buletin Sariputra, 2017, vol.7, pp. 57-61

[19] J. R. Batmetan, " Optimasi Strategi Smart Environment Dalam Mitigasi Bencana Menggunakan Multi-Objective Aco (Mo-Aco) Algorithm", Pasca Sarjana Magister Teknik Informatika Universitas Atma Jaya Yogyakarta, 2016 